\title{
8
}
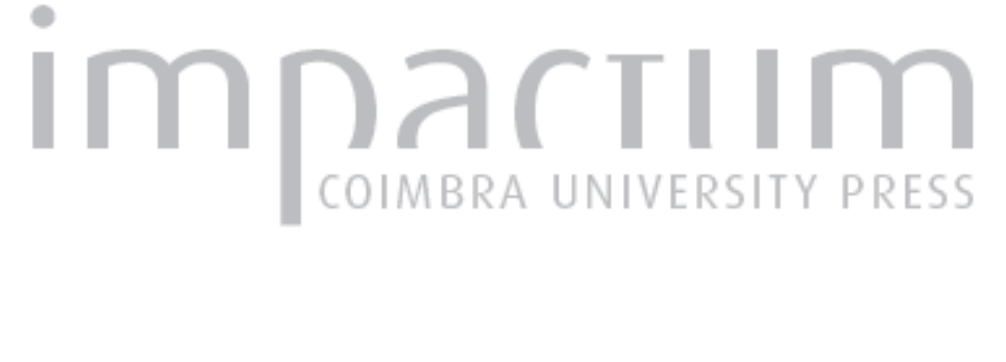

O Tsunami do Índico: 26 de Dezembro de 2004, um dia negro para a história do mundo

\author{
Autor(es): $\quad$ Rebelo, Fernando \\ Publicado por: Associação Portuguesa de Riscos, Prevenção e Segurança \\ URL \\ persistente: \\ URI:http://hdl.handle.net/10316.2/39721 \\ DOI: \\ DOI:http://dx.doi.org/10.14195/1647-7723_12_8 \\ Accessed : $\quad$ 26-Apr-2023 10:15:37
}

A navegação consulta e descarregamento dos títulos inseridos nas Bibliotecas Digitais UC Digitalis, UC Pombalina e UC Impactum, pressupõem a aceitação plena e sem reservas dos Termos e Condições de Uso destas Bibliotecas Digitais, disponíveis em https://digitalis.uc.pt/pt-pt/termos.

Conforme exposto nos referidos Termos e Condições de Uso, o descarregamento de títulos de acesso restrito requer uma licença válida de autorização devendo o utilizador aceder ao(s) documento(s) a partir de um endereço de IP da instituição detentora da supramencionada licença.

Ao utilizador é apenas permitido o descarregamento para uso pessoal, pelo que o emprego do(s) título(s) descarregado(s) para outro fim, designadamente comercial, carece de autorização do respetivo autor ou editor da obra.

Na medida em que todas as obras da UC Digitalis se encontram protegidas pelo Código do Direito de Autor e Direitos Conexos e demais legislação aplicável, toda a cópia, parcial ou total, deste documento, nos casos em que é legalmente admitida, deverá conter ou fazer-se acompanhar por este aviso.

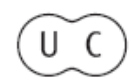




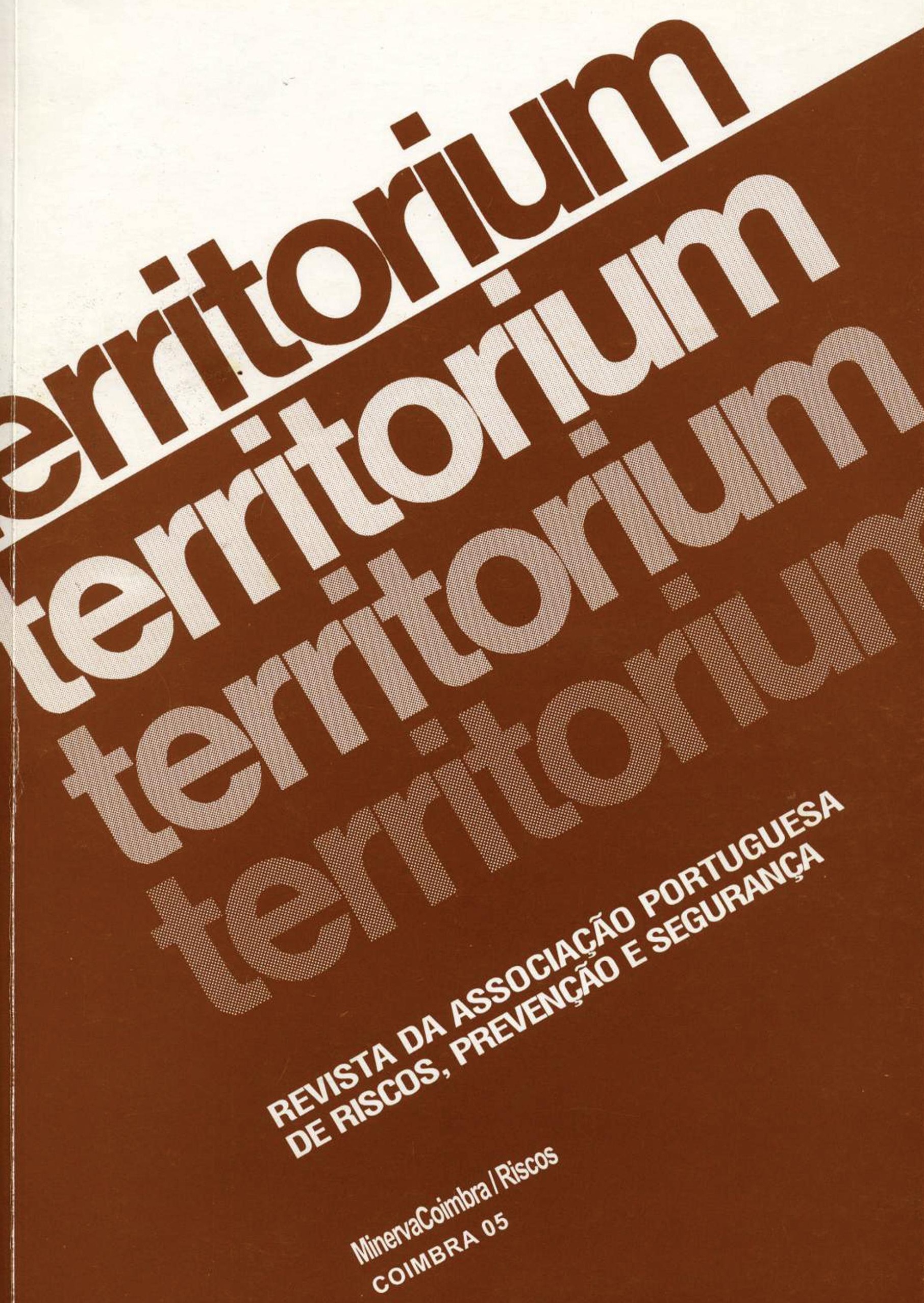


dos riscos, a percepção dos perigos e a gestão das crises no nosso país. A Territorium, continuando a ser publicada pela MinervaCoimbra, já é a revista da Associação Riscos que organizou, por altura do seu lançamento, o I Encontro Nacional de Riscos.
Opresente número da Territorium, $\mathrm{o} 12^{\circ}$, apresenta 3 artigos de engenheiros, 2 de geógrafos, e 1 de um sociólogo, mantendo, assim, a abertura científica que a vem caracterizando.

\section{O Tsunami do Índico. 26 de Dezembro de 2004, um dia negro para a história do mundo*}

\section{Fernando Rebelo}

1. O dia 26 de Dezembro de 2004 irá ficar na memória de milhões de pessoas e será lembrado por numerosos cientistas em todo o mundo. Um tsunami violento, originado por um terramoto com epicentro ao largo da ilha de Sumatra, matou, feriu e assustou gente de aldeias piscatórias, praias, centros turísticos e cidades litorais, sem distinguir entre ricos e pobres. Ondas gigantescas chegaram rapidamente às costas mais próximas do epicentro, na Indonésia e na Tailândia e, logo a seguir, às do Sri Lanka e da Índia. Mantendo a sua força destruidora, atravessaram todo o Oceano Índico e atingiram parte da África oriental. Já com pouca importância, ainda atravessaram o Atlântico e o Pacífico tendo sido registadas, por exemplo, no Brasil e no Japão.

Porque morreram mais de 300000 pessoas com este tsunami? Em 1836, tinha-se verificado um tsunami semelhante quando da explosão do Krakatoa. As costas atingidas terão sido as mesmas. Mas se formos ver os registos das maiores catástrofes mundiais deste tipo, verificamos que, para alguns autores, houve, apenas, 33000 mortos, enquanto para outros poderão ter sido 36000 .

$\mathrm{Na}$ verdade, o risco resulta da consideração de dois factores - o processo em si e a vulnerabilidade. Se a força do processo foi praticamente igual, a vulnerabilidade, que já era grande no século XIX, devido à existência de algumas cidades litorais e muitos portos de pescadores, era, agora, muitíssimo maior pelo crescimento desmesurado dessas cidades e desses portos, atendendo ao elevado crescimento demográfico das populações asiáticas e africanas. Mas terá, ainda, de juntar-se a recente criação de numerosas áreas turísticas, por vezes, concentradas em cidades, muitas vezes, dispersas pelas costas ou porilhas com paisagens mais ou menos paradisíacas. A população exposta ao risco natural era demasiada e, à parte os turistas, na sua esmagadora maioria, muito pobre. As suas habitações nãoestavam preparadas

* Texto publicado na revista Rua Larga. Revista da Reitoria da Universidade de Coimbra, 9, 2005, p. 47-48. para enfrentar um forte ataque das águas do mar. Em regra, baixas e construídas em madeira, taipa ou, apenas, argila, as casas não podiam resistir à violência das águas do mar. Depois, o material que serviu para a construção foi levado pelas águas, em suspensão ou emflutuação, aumentandoa sua violência destruidora ao longo dos espaços percorridos para o interior e que tanto podiam ser vales de rios ou campos de arroz, como podiam ser ruas de cidades. As casas de pedra e de cimento, com vários andares, tal como alguns grandes templos, que não caíram com o terramoto, serviram de refúgio nas partes altas.

Nunca o risco de tsunami se tinha manifestado como tão grande catástrofe. 100000 mortos era o máximo registado no Japão, em 1703 (ZEBROWSKI, 1997).

2. Portugal tem memória de vários terramotos seguidos de tsunamis. Comemoram-se este ano os 250 anos daquele que ficou conhecido como terramoto de Lisboa de 1 de Novembro de 1755. Depois do forte tremor de terra que tanta destruição causou na cidade, mas igualmente em grande parte do país, com especial incidência, na Bacia do Tejo e no Algarve, chegou um tsunami que poderá ter matado ainda mais pessoas do que o desabamento de casas e igrejas. Em 28 de Fevereiro de 1969, após um sismo que teve o seu epicentro na mesma área do de 1755 , ou seja, na área do Banco de Gorringe, a SW do Cabo de São Vicente, também se verificou um tsunami, mas de fraca importância, que não causou danos. Muito mais recente foi o susto vivido por milhares de banhistas que se encontravam no Algarve em Agosto de 1999, quando alguém se lembrou de interpretar como tsunami uma linha paralela ao horizonte, muito próxima do nível do mar, que se via das praias e que parecia ser uma onda em início de rebentação. $\mathrm{O}$ aviso foi lançado e enquanto uns fugiam, outros aproximaram-se para ver... Pedi, na altura a Antunes do Carmo, engenheiro civil e professor da Faculdade de Ciências e Tecnologia da Universidade de Coimbra, para dizer aos geógrafos o que é na realidade um tsunami e explicar, assim, os 
motivos por que aquele fenómeno nunca o poderia ter sido. Como diz no artigo que então publicou na Territorium, Revista de Geografia Física Aplicada no Ordenamento do Território e Gestão de Riscos Naturais, se fosse um tsunami, quando se viu, já não haveria tempo para evacuar qualquer praia. As ondas são difíceis de ver no meio dos oceanos e a sua velocidade de propagação pode ser de centenas de quilómetros por hora; de terra, poderiam ver-se a uns dez ou doze quilómetros de distância, o que tornaria impossível accionar qualquer sistema de alerta eficaz (CARMO, 2000). Também em 26 de Dezembro de 2004 nunca teria sido possível dar um alerta para áreas tão próximas do epicentro com as da província indonésia independentista de Aceh; no entanto, ficou a amargura de não ter sido dado um alerta que permitisse salvar populações da Tailândia, da Índia ou do Sri Lanka.

3. O grande tsunami que atingiu Portugal e de cujas consequências há mais documentação foi, sem dúvida, o de 1 de Novembro de 1755. ZEBROWSKI (1997) coloca-o em quinto lugar numa lista dos tsunamis notáveis, com 10000 mortos. Considera o terramoto responsável por 30000 , colocando-o numa lista em que cita 22 bem mais mortíferos. Se bem que nunca se saiba com exactidão o número de perdas humanas, é de crer que o tsunami de 1755 tenha sido pior do que aqueles números indicam. No Algarve, por exemplo, hánotícias de muitos mortos em Albufeira, na Quarteira, na Praia da Luz (Tavira), tal como se sabe que o mar entrou uma légua na área de Aljezur, três quilómetros em Sagres e outros três no concelho de Loulé, que subiu 30 metros em Alvor e 10 em Lagos (FRAZÃO, 1992).

Impressionante, até porque escrito antes de vermos nos telejornais as terríveis imagens do tsunami do Índico, é o tex to de LUIS ROSA (2004) sobre o que se terá passado em Lisboa - "A vaga imensa galgara a parte baixa da cidade pulando sobre as ruínas, entrando furiosa pelas ruas estreitas, como torrente por desfiladeiro, até atingir a proximidade da porta de Santo Antão, alagando o Rossio. Retirou-se com a mesma fúria com que viera, arrastando as suas presas, pessoas, cadáveres, móveis, destroços, lamentos, angústia e raiva".

\section{Referências bibliográficas:}

CARMO, José S. Antunes do (2000) - "Tsunamis - geração e riscos". Territorium, Coimbra, 7, p. 15-24

FRAZÃO, Mário de Mendóça (1992) - “O Megasismo de 1755 no Algarve". Comunicações, $7^{\circ}$ Congresso do Algarve, 1992, p. 31-44.

ROSA, Luís (2004) - O Terramoto de Lisboa e a Invenção do Mundo, Romance. Lisboa, Editorial Presença, 273 p.

ZEBROWSKI Jr., Ernest(1997)-Perilsofa Restless Planet. Scientific Perspectives on Natural Disasters. Cambridge University Press, 306 p.

\section{Congresso e livro sobre análise e gestão de riscos, segurança e fiabilidade}

\section{Fernando Rebelo}

Entre 11 e 13 de Maio de 2005 realizou-se em Lisboa, no Centro de Congressos do Instituto Superior Técnico, $\mathrm{o} \mathbf{l}^{\circ}$ Encontro Nacional de Riscos, Segurança e Fiabilidade. Tendo o Professor Carlos Guedes Soares como Presidente de uma Comissão Organizadora, onde se encontravam mais 18 individualidades de Universidades e Institutos Politécnicos, mas também de importantes empresas, este Encontro foi promovido pela Secção Portuguesa da ESRA (European Safety and Reliability Association).

Na Sessão de Abertura, além do Presidente da Comissão Organizadora e do Director do Instituto Superior Técnico, falou o Ministro da Ciência e do Ensino Superior, Professor Mariano Gago, que não quis ficar-se pelas palavras de circunstância alusivas ao acontecimento, preferindo entrar na matéria e mostrar às centenas de participantes que também tem consciência dos riscos naturais e tecnológicos e que se preocupa com a percepção dos perigos e com a necessidade de se estar preparado para a gestão das crises. A sua experiência na área da Física e a sua experiênciana área da gestão da investigação científica, juntas, estiveram na base da primeira grande lição do Encontro.

As muitas intervenções que se anunciavam obrigaram os organizadores a dividị os trabalhos por várias salas. Havia quem corresse de uma para outra no sentido de não perder o que lhe interessava. Tal como em qualquer grande Congresso havia salas momentaneamente cheias que logo perdiam metade dos ouvintes porque ao lado outra comunicação era considerada imprescindível. Convidado a colaborar com uma comunicação na área dos "Riscos Naturais e Ambientais", propus uma, intitulada "Riscos Naturais. 